\title{
Triatominae as a Model of Morphological Plasticity under Ecological Pressure
}

\author{
JP Dujardin/ ${ }^{+}$, P Panzera*, CJ Schofield**
}

UMR CNRS-ORSTOM 9926, ORSTOM BP 5045, 911 Av. Agropolis, Montpellier cedex 1, France *Sección Genetica Evolutiva, Facultad de Ciencias, Universidad de la Republica, Montevideo, Uruguay **Department of Infectious and Tropical Diseases, London School of Hygiene and Tropical Medicine, London WC1 E7HT, UK

The use of biochemical and genetic characters to explore species or population relationships has been applied to taxonomic questions since the 60s. In responding to the central question of the evolutionary history of Triatominae, i.e. their monophyletic or polyphyletic origin, two important questions arise (i) to what extent is the morphologically-based classification valid for assessing phylogenetic relationships? and (ii) what are the main mechanisms underlying speciation in Triatominae? Phenetic and genetic studies so far developed suggest that speciation in Triatominae may be a rapid process mainly driven by ecological factors.

Key words: Triatominae - ecological factors - morphological plasticity ECOLOGICAL FORCES AND MORPHOLOGICAL
PLASTICITY

Among the first attempts to examine other characteristics than morphological traits in Triatominae the use of haemolymph electrophoresis raised a new taxonomic question by showing two distinct populations within Triatoma sordida (Actis et al. 1964). Thirty-three years later, T. sordida was confirmed as a complex of isomorphic species both by cytogenetic and isoenzymatic techniques (Panzera et al. 1997, Noireau et al. 1998). These studies showed for the first time that significant biochemical differences could subdivide a recognised morpho-species of Triatoma into different genetic units, although no other sibling species of Triatominae have yet been demonstrated. The apparent rarity of sibling species in Triatominae may reflect the lack of relevant population studies (Frias \& Dujardin 1996), but could also reflect the biological mechanism of sibling species formation, especially if such mechanism implied morphological convergence between two related species competing within the same ecological niche. In this hypothesis, the sibling species of sordida may initially have been two different mor-

This work benefited from international co-operation through the ECLAT network.

${ }^{+}$Corresponding author. Present address: Department of Tropical Diseases, IBBA, ORSTOM La Paz, Casilla Postal 9214 La Paz, Bolivia. Fax: +591-2-22.5846/ 24.3782. E-mail: jpdujard@mail.megalink.com Received 9 June 1999

Accepted 9 August 1999 pho-species which converged by adaptation to the same ecotope (both are currently found in bromeliads and in peridomestic habitats). But because any particular niche tends to be occupied by a single species, sibling species would be less frequent in Triatominae than in other groups as Diptera where they may arise abruptly from a single mutation. Unlike Diptera, chromosomes of Triatominae are holocentric, accepting some damages without lethal consequences (Maudlin 1976) and often with marked intraspecific polymorphism of heterochromatin content (Panzera et al. 1992).

The idea that sibling species in Triatominae reflect morphological convergence, is supported by observation of the morphological, metric and genetic changes of various species in the transition from silvatic to domestic habitat (Dujardin $1998 \mathrm{a} / \mathrm{d})$. The sensory system, for example, in terms of the density of antennal sensilla, becomes progressively simplified in accordance with increasing habitat stability (Catalá 1997); bilateral symmetry becomes relaxed (Fig. 1) (Dujardin \& Casini 1996), as does sexual dimorphism (Fig. 2) (Dujardin et al. 1999a); and a general reduction in body size may also be seen (Dujardin et al. 1997a,b, 1998b,c, 1999b).

Since morphology seems clearly modulated by ecological factors, we may assume that these same factors may produce divergent morphologies within a single species, or amongst closely related species. A well documented example comes from analysis of relationships between three species: $T$. infestans, T. platensis and T. delpontei. T. infestans is well known as the main vector of Chagas disease in the Southern Cone of South America, where it is typically found in the cracks and crevices of 


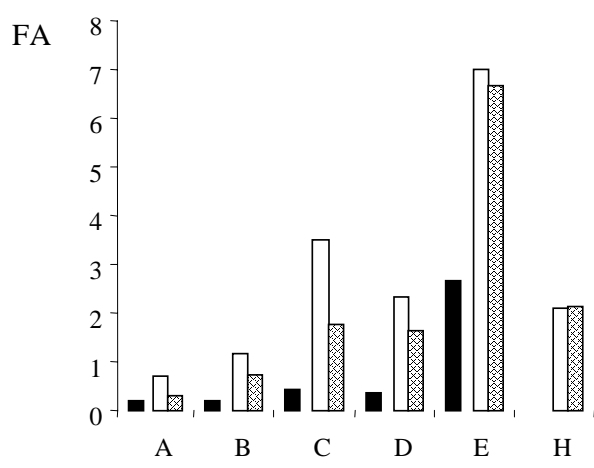

Triatoma sordida, G2, 18 domestic specimens

Triatoma infestans, 12 female domestic specimens

Triatoma infestans, 20 male domestic specimens

Fig. 1: values of fluctuating asymmetry (FA) corrected for measurement error according to Palmer and Strobeck (1986). G2, one of the two sibling species of Triatoma sordida. Silvatic specimens of $T$. sordida are not visible on the figure since they showed no significant asymmetry. All these specimens were kindly provided by F Noireau, IRD.

poor quality rural houses, emerging at night to feed on the sleeping occupants. In contrast, T. platensis and $T$. delponte $i$ are ornithophilic arboreal species, quite unimportant in the transmission of human Chagas disease (Salvatella 1986, 1987). T. platensis commonly infests the woven stick nests of furnariid weaver birds (Anumbius spp.) in northern Argentina, Paraguay, Uruguay and southern Brazil, but has also been found in peridomestic habitats such as chicken coops. T. delpontei seems more ecologically restricted, found almost exclusively in woven stick nests of colonial monk parrots (Myiopsitta monarcha), but occupying a similar geographical range to $T$. platensis. The genetic distance computed for 24 electrophoretic loci was higher between the morphologically and ecologically similar T. platensis and T. delponte $i$ than between $T$. platensis and T. infestans, raising questions about the evolutionary relationships between these species previously derived from morphological traits (Pereira et al. 1996). Moreover, the isoenzyme studies were in agreement with previous interfertility (Usinger et al. 1966) and cytogenetic studies (Panzera et al. 1995), and was recently confirmed by DNA studies (García \& Powels 1998).

This case study, as well as the rapid morphological changes associated with domestic adaptations, suggested that ecological factors may be the main force driving speciation in Triatominae (Pereira et al. 1996). More importantly, it also suggested that morphological differentiation could be
Rhodnius domesticus

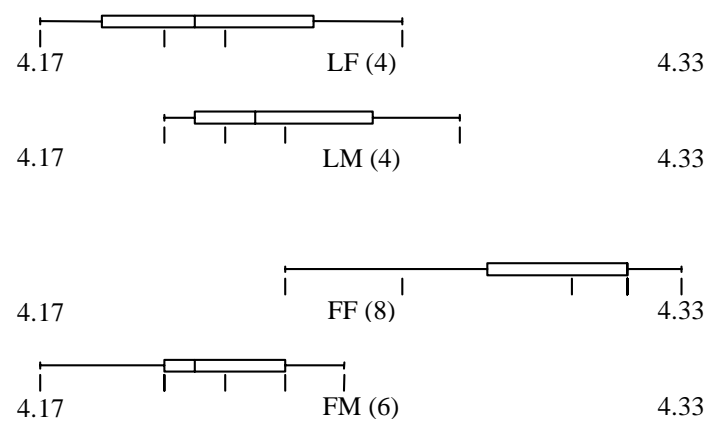

Triatoma infestans

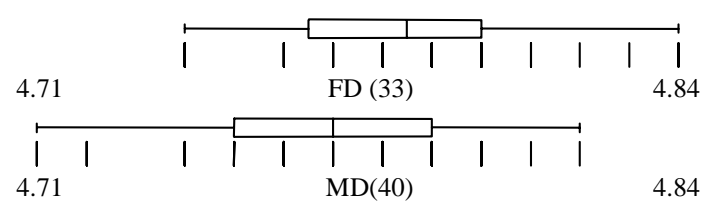

4.71

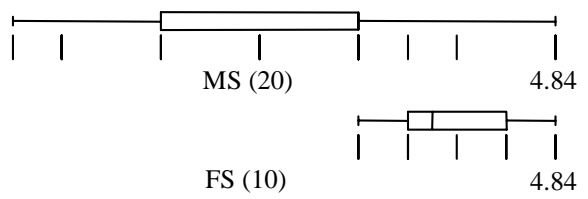

4.71

FS (10)

4.84

Fig. 2: female (F) and male (M) specimens of Rhodnius domesticus (top), either reared in laboratory (LF, LM) or recently collected in the field (FF, FM), aligned along the first principal component (PC1) as an estimator of global size (head measurements). Female (F) and male (M) specimens of Triatoma infestans (bottom), collected in house (FD, MD) or in silvatic ecotopes of Cochabamba (FS, MS), aligned along the PC1as an estimator of global size (head measurements).

quicker than the installation of reproductive or genetic barriers. This latter idea is not new: it was formulated by Usinger et al. (1966) as the conclusion of many interfertility experiments. It was contained also in the conclusion of Gorla et al. (1997) suggesting a New World origin of the Old World Triatoma. According to these authors, the New World members of the genus Triatoma would have T. rubrofasciata as unique ancestor. This species seems to have been spread from the Americas a few centuries ago, and subsequently specialised into the seven recognised species of Triatoma found in the Asian region (Gorla et al. 1997). This iconoclastic idea relies on the assumption of relatively rapid morphological changes. 


\section{EVOLUTIONARY IMPLICATIONS}

Rapid morphological changes - either convergent or divergent - associated with ecological adaptation, help to explain discordance between genetic and phenetic differentiation, and provides a new basis for developing the species concept in Triatominae.

\section{Ecological species}

Species with consistent morphological differences would arise through divergent ecological adaptation. In other words, morphological species of Triatominae would be "ecological species", a vision which fits with the concept of "evolutionary units" (Wiley 1989) where two populations become different species if they follow distinct evolutionary fates. Such an idea does not preclude the existence of important genetic differences, but implies a different evolutionary direction taken by some populations. The idea implies that recent "evolutionary units" would be still very close genetically, which is probably the case of the $T$. infestans, T. platensis and T. delpontei species group described above.

This could also be the case of T. infestans and T. melanosoma. T. infestans melanosoma Martínez, Olmedo \& Carcavallo 1987 has been recently elevated to species rank (Lent et al. 1994) although its species rank could not be validated by corresponding genetic differences. Isoenzyme electrophoresis showed no significant differences between infestans and melanosoma and no differences were revealed by cytogenetic studies or by mtDNA analysis (Monteiro et al., this issue). Crossing experiments revealed interfertility (Cleber, pers. comm.), and morphometric studies showed between infestans and melanosoma differences of the same order as those found between conspecific geographical populations of infestans (Fig. 3). The ecology of $T$. melanosoma is poorly known, but from the hypothesis advanced here we can predict it should be somewhat different from that of $T$. infestans.

Noireau et al. (1997) recently revealed the existence of obscure dark morphs of $T$. infestans in the Bolivian Chaco. This form has a chromatic pattern somewhat intermediate between T. infestans and T. melanosoma. It is found in tree holes, probably associated with wild rodents. However, although morphometric analysis could differentiate the two forms, no isoenzymatic differences nor reproductive isolation could be found.

In the genus Rhodnius, the small-sized species $R$. ecuadoriensis, living in palm trees of Ecuador and Peru and adapting to the domestic habitat in some areas, has been shown by isoenzymes
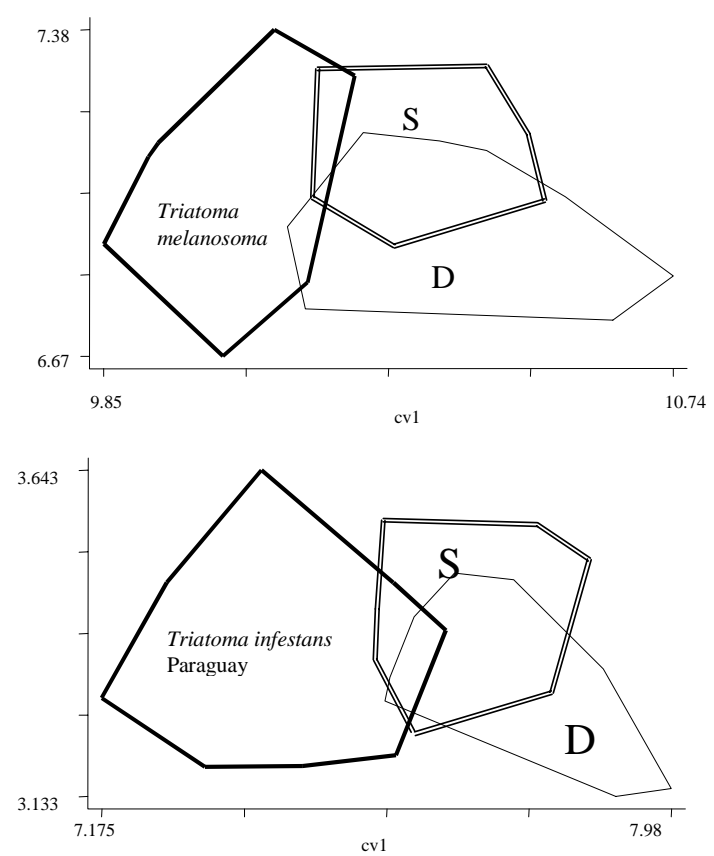

Fig. 3: discriminant analyses of wing shape showing that differences between Bolivian Triatoma infestans, either domestic (D) or silvatic (S) ones, and T. melanosoma (top) are compatible with simple geographic variation within $T$. infestans (bottom). S: silvatic sample of $T$. infestans (19 wings) from Cochabamba (Bolivia); D: domestic sample of $T$. infestans from Cochabamba. T. melanosoma (23 wings) were laboratory specimens (Prof. J Jurberg, Fiocruz, RJ, Brazil). T. infestans from Paraguay (65 wings) were field specimens kindly provided by Dr A Rojas de Arias (Paraguay). "Shape" was estimated by double centering of the log-transformed measurements.

(Chavez et al. 1999) and mtDNA sequencing (Monteiro, pers. comm.) to be closely related to a large-sized, undescribed species occupying other palm trees in parts of Colombia (Tolima).

\section{Morphological plasticity and polyphyletism}

Rapid morphological changes in response to different ecological factors could mislead our perception of genetic differences among some species. And it could do so in two ways. Morphologically differentiated species could have similar genetic background, but conversely, because of the polyphyletic structure of Triatominae (Schofield 1988, Stothard et al. 1998, Lyman et al. 1999), morphologically close species could exhibit important genetic differences. Accepting indeed that the development of hematophagy and adaptations to more stable habitat are evolutionary forces homogenising external morphology (Schofield et al., this issue), some apparently similar species could have evolved from well differentiated predators and thus could present more genetic differ- 
ences than expected. For example, species of Rhodnius, all of arboreal habitats, are similar in overall morphological features. They have no discrete characters allowing clear differentiation, but three species groups can be distinguished within the genus by important genetic distances (Fig. 4, Chavez et al. 1999). These genetic differences, confirmed by a phylogenetic analysis using metric traits (Dujardin 1999b), could imply a relatively ancient separation between species occupying different geographical areas, but they could also reflect genetic differences acquired by their predatory ancestors prior to the development of hematophagy, and thus before morphological convergence.

T. brasiliensis and T. petrochii occur in the arid northeastern states of Brazil, generally in rock piles associated with the Kerodon rupestris (Lent \& Wygodzinsky 1979). These two species are morphologically and ecologically similar, though $T$. brasiliensis also may occupy domestic structures. Isoenzyme data not only confirmed their specific status but also suggested they have been evolving independently for considerable time (Monteiro et al. 1998).

The recently described Mepraia gajardoi Frias, Henry, Gonzales 1998 and Rhodnius stali (Lent, Jurberg, Galvão 1993) may be similar cases. Both were long included with their sister species: $M$. gajardoi with $M$. spinolai and $R$. stali with $R$. pictipes, but both show consistent genetic differ-

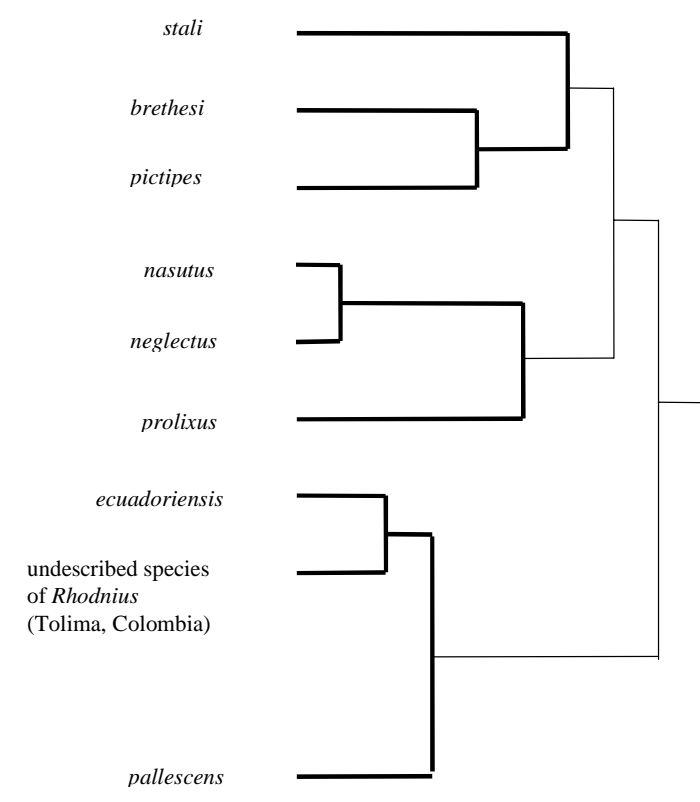

Fig. 4: an UPGMA tree derived from Jaccard distances between Rhodnius species, after isoenzyme analysis (12 enzymes, 17 loci). ences with their corresponding sister species, such as reproductive isolation and cytogenetic differences between M. gajardoi and M. spinolai (Frias et al. 1998), or relatively large Nei's genetic distances between $R$. stali and R. pictipes (Chavez et al. 1999).

\section{Sibling species}

Sibling species would represent the extreme case where two distinct lineages competing within the same ecological niche arrived at identical morphology. In this hypothesis, sibling species of Triatominae would correspond to the special case where one species did not eliminate the other one. The prediction would be that sibling species are more likely to be found in the same ecological niche, and would be less frequent than in other insect groups in as much as interspecific competition rarely admits two winners. One way to verify such hypothesis would be to estimate genetic distances between sibling species. According to our hypothesis, this genetic distance should be consistent with two well differentiated species. In fact, genetic distance between the sibling species of $T$. sordida was higher than between $T$. infestans and T. melanosoma, or between T. infestans and $T$. platensis. RAPD studies even put one of the sordida species closer to T. infestans than to its sibling counterpart (Sanchez, pers. comm.).

\section{CONCLUSION}

Triatominae seem able to develop rapid morphological changes in response to adaptation to new habitats. Within a polyphyletic structure, their morphological plasticity seems modulated by ecological pressure. We suggest that because of rapid morphological adaptation to new conditions, new evolutionary units may arise that still share a common genetic background. Such evolutionary units may be morphologically recognisable, ecologically defined, and as such are natural targets for operational measures directed against vectors of Chagas disease. Conversely however, similar morphs may be derived from different genetic units adapting to the same ecotope. At the extreme, they become sibling species. Since it is unusual to find two species occupying the same ecological niche, this extreme case would be less frequent. If morphological similarities in Triatominae reflect more their ecological niche rather than common ancestry, morphology should be regarded with caution as the main criterion for phylogenetic studies in Triatominae (Pereira et al. 1996). The same caution can be applied to morphological differences. If these arise mainly in response to ecological variety, they would provide poor prediction on the underlying genetic differences. 


\section{REFERENCES}

Actis AS, Traversa OC, Carcavalho RU 1964. Estudios taxonómicos sobre el genero Triatoma Laporte mediante la electrophoresis de la linfa. An Esc Nac Ciencias Biol XIII 1-4: 97-106.

Catalá S 1997. Antennal sensilla of Triatominae (Hemiptera, Reduviidae): a comparative study over five genera. Intern J Insect Morphol Embriol 26: 67-73.

Chavez T, Moreno J, Dujardin JP 1999. Isoenzyme electrophoresis of Rhodnius species: a phenetic approach to relationships within the genus. Ann Trop Med Parasitol in press.

Dujardin JP 1998a. Population genetics and the natural history of domestication in Triatominae. Mem Inst Oswaldo Cruz 93 (Suppl. II): 34-36.

Dujardin JP, Casini C 1996. Morphometry of Triatoma infestans, p. 53-54. In CJ Schofield, JP Dujardin, J Jurberg (eds), Proceedings of the International Workshop on Population Genetics and Control of Triatominae, Santo Domingo de los Colorados, Ecuador, INDRE, Mexico City.

Dujardin JP, Bermudez H, Casini C, Schofield CJ, Tibayrenc M 1997a. Metric differences between silvatic and domestic Triatoma infestans (Heteroptera: Reduviidae) in Bolivia. J Med Entomol 34: 544-551.

Dujardin JP, Bermudez H, Schofield CJ 1997b. The use of morphometrics in entomological surveillance of sylvatic foci of Triatoma infestans in Bolivia. Acta Tropica 66: 145-153.

Dujardin JP, Chavez T, Machane M, Solis S. 1999b. Size, shape and genetics. Sexual dimorphism and environment. In CJ Schofield \& C Ponce (eds), Proceedings of the Second International Workshop on Population Biology and Control of Triatominae, Tegucigalpa, Honduras, INDRE, Mexico City (in press).

Dujardin JP, Forgues G, Torrez M, Martinez E, Cordoba C, Gianella A 1998b. Morphometrics of domestic Panstrongylus rufotuberculatus in Bolivia. Ann Trop Med Parasitol 2: 219-228.

Dujardin JP, Munoz M, Chavez T, Ponce C, Moreno J, Schofield CJ 1998c. The origin of Rhodnius prolixus in Central America. Med Vet Entomol 12: 113-115.

Dujardin JP, Schofield CJ, Tibayrenc M 1998d. Population structure of Andean Triatoma infestans: allozyme frequencies and their epidemiological relevance. Med Vet Entomol 12 : 20-29.

Dujardin JP, Steindel M, Chavez T, Martinez E, Schofield CJ, 1999a. Changes in the sexual dimorphism of Triatominae in the transition from natural to artificial habitats. Mem Inst Oswaldo Cruz, in press.

Frias D, Dujardin JP 1996. Deteccion de la variacion genética a nivel poblacional a traves del metodo de electroforesis, p. 65-71. In CJ Schofield, JP Dujardin, J Jurberg. (eds), Proceedings of the International Workshop on Population Genetics and Control of Triatominae, Santo Domingo de los Colorados, Ecuador, INDRE, Mexico City.

Frias D A, Henry A A, Gonzalez C R 1998. Mepraia gajardoi: a new species of Triatominae (Hemiptera: Reduviidae) from Chile and its comparison with
Mepraia spinolai. Rev Chil Hist Nat 71: 177-188.

García AG, Powels JR 1998 Phylogeny of species of Triatoma (Hemiptera: Reduviidae) based on Mitochondrial DNA Sequences. J Med Entomol 3: 232238.

Gorla DE, Dujardin JP, Schofield CJ 1997. Biosystematics of Old Word Triatominae. Acta Tropica 63: 127 140.

Lent H, Wygodzinsky P 1979. Revision of the Triatominae (Hemiptera, Redfuviidae) and their significance as vectors of Chagas disease. Bull Am Mus Nat Hist 163: 125-520.

Lent H, Jurberg J, Galvão C 1993. Rhodnius stali N. SP., afim de Rhodnius pictipes stal, 1872 (Hemiptera, Reduviidae, Triatominae). Mem Inst Oswaldo Cruz 4: 605-614.

Lent H, Jurberg J, Galvão, Carcavallo RU 1994. Triatoma melanosoma, Novo Status para Triatoma infestans melanosoma Martinez, Olmedo \& Carvallo, 1987 (Hemiptera: Reduviidae). Mem Inst Oswaldo Cruz 3: 353-358.

Lyman DF, Monteiro FA, Escalante AA, Cordon-Rosales C, Wesson DM, Dujardin JP, CB Beard 1999. Mitochondrial DNA sequence variation among triatomine vectors of Chagas disease. Am J Trop Med Hyg 60: 377-386.

Maudlin I 1976. The inheritance of radiation induced semi-sterility in Rhodnius prolixus. Chromosoma (Berl.) 58 : 285-306.

Monteiro FA, Costa J, Solé-Cava AM 1998. Genetic confirmation of the specific status of Triatoma petrochii (Hemiptera: Reduviidae: Triatominae). Ann Trop Med Parasitol 92: 897-900.

Noireau F, Flores R, Gutierrez T, Dujardin JP 1997. Detection of silvatic dark morphs of Triatoma infestans in the Bolivian Chaco. Mem Oswaldo Cruz 5: 583-584.

Noireau F, Gutierrez T, Zegarra M, Flores R, Brenière F, Dujardin JP 1998. Cryptic speciation in Triatoma sordida (Hemiptera: Reduviidae) from the Bolivian Chaco. Trop Med Internl Health 5: 364-372.

Palmer AR, Strobeck C 1986. Fluctuating asymmetry: measurement, analysis, patterns. Ann Rev Ecol Syst 17: 391-421.

Panzera F, Alvarez F, Sanchez-Rufas J, Perez R, Suja JA, Scvortzoff E, Dujardin JP, Estramil E, Salvatella $\mathrm{R}$ 1992. C-heterochromatin polymorphism in holocentric chorosomes of Triatoma infestans (Hemiptera: Reduviidae). Genome 35: 1068-1074.

Panzera F, Hornos S, Pereira J, Cestau R, Canale D, Diotaiuti L, Dujardin JP, Perez R 1997. Genetic variability and geographic differentiation among three species of triatomine bugs (Hemiptera-Reduviidae). Am J Trop Med Hyg 6: 732-739.

Panzera F, Perez R, Panzera Y, Alvarez F, Scvortzoff E, Salvatella R 1995. Karyotype evolution in holocentric chromosomes of three related species of Triatominae (Hemiptera: Reduviidae). Chrom Res 3: 143-150.

Pereira J, Dujardin JP, Salvatella R, Tibayrenc M 1996. Enzymatic variability and phylogenetic relatedness among Triatoma infestans, T. platensis, T. delpontei and T. rubrovaria. Heredity 77: 47-54. 
Salvatella R 1986. Triatoma delpontei (Romanha \& Abalos, 197) (Hemiptera-Reduviidae). Nueva especie de triatomineos para el Uruguay. Rev Urug Pat Clinica 22: 58.

Salvatella R 1987. Distribución de Triatoma platensis Neiva, 1913. (Hemiptera-Triatominae) en Uruguay. Rev Soc Urug Parasitol 1: 51-56.

Schofield CJ 1988. Biosystematics of the Triatominae. Biosystematics of Haematophagous Insects 37: 285-312.

Stothard JR, Yamamoto Y, Cherchi A, Garcia AL, Valente SAS, Schofield CJ, Miles MA 1998. A pre- liminary survey of mitochondrial sequence variation in Triatominae (Hemiptera: Reduviidae) using polymerase chain reaction-based single strand conformational polymorphism (SSCP) analysis and direct sequencing. Bull Entomol Res 88: 553-560

Usinger RL, Wygodzinsky P, Ryckman R 1966. The biosystematics of Triatominae. Ann Rev Entomol 11: 309-330.

Wiley EO, 1989. Phylogenetics: the Theory and Practice of Phylogenetic Systematics, Wiley-Interscience, $439 \mathrm{pp}$. 